\title{
Less Well-Known Consequences of the Long-Term Use of Opioid Analgesics: A Comprehensive Literature Review
}

Aleksandra Kotlińska-Lemieszek (iD) ${ }^{1,2}$ Zbigniew Żylicz ${ }^{3}$

'Chair and Department of Palliative Medicine, Pharmacotherapy in Palliative Care Laboratory, Poznan University of Medical Sciences, Poznan, Poland; ${ }^{2}$ Heliodor Święcicki University Hospital, Poznan, Poland; ${ }^{3}$ Institute of Medical Sciences, Medical College, University of Rzeszów, Rzeszów, Poland
Correspondence: Aleksandra

Kotlińska-Lemieszek

Chair and Department of Palliative

Medicine, Pharmacotherapy in Palliative

Care Laboratory, Poznan University of

Medical Sciences, Heliodor Święcicki

University Hospital, Os. Rusa 55, Poznan,

61-245, Poland

Tel +48608079698

Fax +48618738303

Email alemieszek@ump.edu.pl
Background: The adverse effects of short-term opioid analgesics are well known and acknowledged; however, the spectrum of the sequelae of long-term use seems less clear. Some effects may remain undetected but still have the potential to cause harm and reduce patients' quality of life.

Objective: To review the literature on the adverse effects of long-term opioid therapy.

Methods: We performed a quasi-systematic search, analyzing articles published in the MEDLINE database between January 2000 and March 2021 that identified adverse effects of opioids used for chronic pain treatment.

Results: Growing evidence indicates that there are multiple serious adverse effects of opioid treatment. Long-term opioid use may have significant effects on the endocrine, immune, cardiovascular, respiratory, gastrointestinal, and neural systems. Studies show that long-term opioid treatment increases the risk of fractures, infections, cardiovascular complications, sleep-disordered breathing, bowel dysfunction, overdose, and mortality. Opioids may potentially affect cancer development. Most consequences of the long-term use of opioids have been identified in studies of patients with non-malignant pain.

Conclusion: Studies indicate that long-term use of opioids increases the risk of drug-related events in a significant number of patients. Clinicians should be aware of these complications associated with prescribing opioids, discuss them with patients, prevent complications, if possible, and diagnose them early and manage adequately. More human studies are needed to assess the risk, including trials with individual opioids, because they have different adverse effect profiles.

Keywords: opioids, chronic pain, adverse effects, long-term treatment, safe therapy

\section{Introduction}

Opioids are widely used for the treatment of pain. Their consumption has increased significantly in the last two decades, and they are now used not only for advanced cancer patients but also for those in the earlier stages of the disease and in many individuals with pain due to non-malignant diseases. Survival rates for patients with cancer have also improved notably, and many of these cancer survivors still need opioid treatment. Although the adverse effects of opioids used for a short time are well known and acknowledged, the sequelae of the long-term use of these drugs are less known and understood by many clinicians. ${ }^{1-6}$ This issue gains special importance in the view of growing need for adequate pain treatment in aging societies in developed countries, worldwide undertreatment of pain and coexisting problems of 
opioid crises in some regions of the world in the recent decade. $^{7-9}$ This manuscript will highlight current knowledge in the area of the long-term adverse effects of opioids used for pain treatment.

\section{Materials and Methods}

We performed a quasi-systematic search, analyzing papers published between January 2000 and March 2021 in the MEDLINE database identified after typing a combination of "opioid, adverse effects, long-term therapy, chronic pain, hypogonadism, endocrinopathies, fractures, immunomodulation, immunosuppression, cancer development, cancer growth, infections, cardiovascular events, bowel dysfunction, narcotic bowel syndrome, sleep-disordered breathing, overdose, death". From a plethora of search results, we selected papers that examined the use of opioids for chronic non-cancer and cancer pain, including pain induced by antitumor therapy. We referred "long-term" opioid therapy to the treatment of chronic pain, lasting longer than 3 months. We excluded trials investigating extra-medical use of opioids, non-human studies and selected randomized controlled trials (RCTs), case-control studies, cohort studies, systematic reviews and meta-analyses. However, if such trials were not found, we referred to preclinical studies in order to present important issues related to opioid use which needs further clinical investigations.

\section{Results}

The review of the literature indicates that opioids used for the treatment of chronic pain may cause a varied spectrum of potentially serious adverse effects. Opioids have significant effects on the endocrine, immune, cardiovascular, respiratory, gastrointestinal and neural systems. ${ }^{10-20}$ They increase the risk of fractures, infections, cardiovascular complications (including myocardial infarction), sleep disturbances and sleep-disordered breathing, bowel dysfunction, overdose and mortality due to opioid overdose or other causes. $^{15-18,21-27}$ Opioids may potentially affect cancer development. ${ }^{28-30}$ Most adverse effects of the longterm use of opioid analgesics have been identified in studies of patients with non-malignant pain. Some adverse effects have been studied only in animal models and their importance in humans has not been fully confirmed.

\section{Endocrine Effects}

Most publications on opioid-induced endocrinopathies concern hypogonadism (opioid-induced hypogonadism, OIH). ${ }^{10-13,31-33}$ Opioids inhibit the hypothalamic-pituitary- gonadal (HPG) axis by acting primarily on mu opioid receptors in the hypothalamus. They inhibit the pulsatile secretion of gonadotropin-releasing hormone from the hypothalamus and decrease the secretion of luteinizing hormone and to a lesser extent follicle-stimulating hormone from the pituitary gland, which results in a fall in testosterone and estradiol release by the gonads. ${ }^{31,34-36}$ The symptoms of sex hormone deficiency may manifest as loss of libido, impotence in males, menstrual cycle disturbance in women and infertility. Opioids may also increase prolactin levels and be responsible for galactorrhea and gynecomastia. ${ }^{31,34}$ All these symptoms may be accompanied by the loss of energy and depression. ${ }^{3,32,35}$ Of note, hypogonadism may be associated with increased sensitivity to pain and poor pain control. ${ }^{36-40}$ Long-term use of opioids may result in decreased muscle mass and bone loss. ${ }^{37,41}$

Decreased levels of sex hormones after opioid use were first described in subjects abusing heroin and during methadone maintenance. ${ }^{42,43}$ Most papers concerning $\mathrm{OIH}$ in patients treated for pain have been conducted with men, and there are many fewer reports concerning the effects of opioids on the endocrine glands in women. ${ }^{3,10-12,36,37,44-46}$ According to a number of analyses, OIH occurs in $19-86 \%$ of men using opioids for chronic non-malignant pain depending on the criteria of hypogonadism applied, opioid type, duration of use and the characteristics of population. ${ }^{32,37,47-49}$ According to a systematic review clinical symptoms of hypogonadism (oligo/amenorrhea) were present in $23-81 \%$ of women aged 18-55 years treated with opioids for chronic non-malignant pain for 1 month or longer. ${ }^{11}$ An association between opioids and hypogonadism was also demonstrated in cancer patients and cancer survivors. ${ }^{13,35,49,50}$ For example, $64 \%$ of patients with advanced cancer had a low level of testosterone, which correlated with the Hospital Anxiety and Depression Scores. ${ }^{35}$ Hypogonadism was also found in 18 out of $20(90 \%)$ male cancer survivors treated with opioids for over 1 year (compared to $40 \%$ for the control group). ${ }^{49}$

The degree of hormonal deficiency may depend on the individual opioid used. In a retrospective cohort analysis, the odds of androgen deficiency were higher in men using fentanyl, methadone or oxycodone as compared with individuals using hydrocodone. ${ }^{51}$ Some reports indicated that buprenorphine and tapentadol may have less of an effect on the levels of sex hormones. ${ }^{11,37,52-55}$ The risk of OIH is higher with higher opioid doses ( $>100 \mathrm{mg}$ morphine equivalent daily dose, MEDD) and the use of long-acting opioids as compared to short-acting. ${ }^{12,13,37,47,50,51,56-58}$ Most probably, when short-acting opioids are used, 
pulsatile hormone release takes place between the doses and thus prevents hypogonadism. ${ }^{51,57}$

Supplementation with sex hormones may improve sexual functioning and should be considered under close specialist supervision whenever opioid dose reduction or opioid cessation is not feasible. ${ }^{3,31,59}$ Of interest, hormone supplementation may reverse hyperalgesia and improve pain control in patients treated with opioids. ${ }^{37,38,60,61}$

In addition to suppression of the HPG axis, opioids can inhibit the hypothalamic-pituitary-adrenal (HPA) axis through inhibition of corticotropin-releasing hormone, resulting in decreased adrenocorticotropin (ACTH) release. ${ }^{3,62,63}$ Both short-term and long-term use of opioids for pain treatment were demonstrated to cause hypocortisolism that in some cases manifested as adrenal crisis. ${ }^{46,48,63-69}$ It should be borne in mind that cortisol levels are increased in patients suffering pain, which may counteract opioid-induced hypocortisolism. Opioids may, however, disturb ACTH and cortisol diurnal rhythms and decrease the adrenal response to hypophyseal stimulation. ${ }^{66,68-70}$ Reports show that cortisol concentrations below normal levels occur in $9-29 \%$ of subjects using opioids in long-term therapy. ${ }^{48,62,71}$ Adrenal insufficiency was described after administration of morphine, diamorphine, hydromorphone, fentanyl, tramadol and loperamide. ${ }^{3,62,63}$

Opioid therapy may also cause hormonal changes of less clinical significance. The data regarding alterations in growth hormone and thyroid-stimulating hormone secretion remain inconclusive. ${ }^{3,32,46,48,50}$

\section{Osteoporosis and Increased Fracture Risk}

Decreased bone density in patients treated with opioids and increased risk of fractures have been well documented..$^{3,72-75}$ In patients using long-term opioids, the prevalence of osteopenia and osteoporosis may reach $50 \%$ and $20 \%$, respectively ${ }^{3,41,58}$ These phenomena can be related to hypogonadism (see above), but also to the $\mu$ receptor-related inhibition of osteoblast activity and interference of opioids with bone turnover. ${ }^{72}$

A meta-analysis of 18 cohort or case-control studies concerning patients with chronic non-cancer pain showed that in patients treated for pain with opioids, the overall risk of fractures increased by about $80 \%{ }^{22}$ The higher risk of fractures has been confirmed for a number of opioids (morphine, oxycodone, fentanyl, tramadol and codeine, among others) and demonstrated to be greater with higher doses and the use of short-acting opioids. ${ }^{21,72,76,77}$ Surprisingly, according to some studies, the risk of fractures is highest in the first 2 to 3 weeks of treatment (a more than six-fold increase in the risk), which suggests association of these events with falls due to sedation and dizziness caused initially by opioids. ${ }^{21,78}$ However, osteopenia and osteoporosis may be the cause of bone fractures that occur later in the course of the treatment. ${ }^{3,72,77}$

\section{Immunomodulatory Effects of Opioids}

Opioids influence cellular and humoral immunity in a complex way. During the course of the inflammatory process, endogenous opioids are released by activated leucocytes and play the role of mediators in the immune system, influencing the proliferation of $\mathrm{T}$ lymphocytes and regulating the activity of natural killer (NK) cells, the synthesis of antibodies and the phagocytic function of macrophages. ${ }^{79-81}$ Most publications relating to the immunomodulatory effect of exogenous opioids were preclinical experiments conducted with morphine. ${ }^{82}$ Morphine may inhibit NK cell cytotoxicity, the differentiation and function of macrophages and progenitor lymphatic cells, chemotactic and phagocytic activity of granulocytes and monocytes, proliferation of $\mathrm{T}$ and $\mathrm{B}$ cells and the expression of pro-inflammatory cytokines. ${ }^{14,79,80}$ Experimental studies indicate that individual opioids differ in their effects on the immune system, and the effect is also related to the dose used and duration of treatment. ${ }^{82-84}$ Morphine was demonstrated to have a strong immunosuppressive effect. ${ }^{14,81,82,85}$ Fentanyl showed a dual effect on immune system. Most studies indicated strong immunosuppressive effect of fentanyl similar to that of morphine. Interestingly, some experiments in animal models showed disappearance of fentanyl-induced immunosuppression after a few days of continuous use of this drug, suggesting development of tolerance to this effect. ${ }^{86,87}$ Large fentanyl doses administered perioperatively in human studies $(75-100 \mu \mathrm{g} / \mathrm{kg})$ caused prolonged suppression of NK cell cytotoxicity as compared to low doses $(1-5 \mu \mathrm{g} / \mathrm{kg}) .{ }^{84}$ In contrast, investigations assessing the effect of intravenous fentanyl in healthy volunteers showed increased cytotoxicity of NK cells related to an increase in the proportion of this fraction of cells in the circulation (and not their activity) ${ }^{88,89}$ Oxycodone and methadone demonstrated a weak effect on the immune system. ${ }^{80-82,90}$ Buprenorphine was shown to have a minor or no effect. ${ }^{86,91,92}$ In contrast to most opioids, tramadol appears to have intrinsic immunostimulatory properties, which may be related to its serotonergic activity. ${ }^{93}$ In experimental studies, tramadol enhanced NK cytotoxicity, proliferation of 
lymphocytes and cytokine production but had no effect on phagocytic capacity of polymorphonuclear cells and monocytes and prevented surgery-induced suppression of NK cell activity. ${ }^{79,80,82,94-96}$

\section{Influence on Neoplastic Transformation}

Multiple experimental studies show that opioids can promote the processes of angiogenesis, proliferation, adhesion, infiltration and the formation of distant metastases. ${ }^{28,29,97}$ These effects are diverse and depend on the individual opioid and the doses used. ${ }^{29,30,95,98}$ In line with these observations, some investigations demonstrated that the opioid antagonist methylnaltrexone (MNTX) may inhibit tumor growth and metastatic behaviors in certain cancers. ${ }^{98,99}$ In contrast to the above observations, some experiments demonstrated a potentially protective effect of some opioids in cancer. For example, methadone was shown to induce apoptosis of leukemia cells and increase sensitivity of some cancer cells to chemotherapy. ${ }^{100-102}$ Also morphine, fentanyl and oxycodone were shown to exert proapoptotic effects on cancer cells and inhibit metastatic mechanisms in experimental models. ${ }^{103-107}$

This preclinical evidence confirms that opioids may modify cancer progression, although whether the balance of effects favors increased or decreased risk of cancer progression in individual situations remains unclear. In recent years, multiple publications in humans aiming to define the association of the use of opioids and cancer development have been published. Their interpretation is, however, difficult and definite answers to these concerns cannot be given so far. Different outcomes in these experiments reflect multiple contributing factors and their limitations. The most important of these studies are summarized below.

$\mathrm{Mu}$ opioid receptors were demonstrated to be overexpressed in several human malignancies and their higher expression was demonstrated to be associated with cancer progression and a shorter survival. ${ }^{28,108-111}$ In line with these observations, a longer survival after mastectomy in women with polymorphism of single nucleotide A118G, which determines a lower sensitivity to morphine, was concluded; however, the study did not provide information about opioid use by the patients, which is its important limitation. $^{112}$

The most abundant data on cancer promotion concern the impact of analgesia used during tumor resection. Many, but not all, authors indicated that opioid-sparing regional techniques may be associated with a favorable outcome as compared to systemic analgesia. ${ }^{113-117}$ This studies are criticized, however, due to methodological limitations and the fact that multiple other coexisting factors (such as surgery, pain, and some anesthetic drugs used, among others) may cause immunosuppression in this clinical setting. ${ }^{115,118-120}$ In a recent multicenter RCT including over 2000 women having potentially curative primary breast cancer resection, regional anesthesia-analgesia did not reduce breast cancer recurrence compared with general anesthesia and systemic opioids. ${ }^{121}$

An association between opioid use and survival was evaluated in a number of other studies in cancer patients, but most were stated to be inconclusive. ${ }^{109,122-128}$ According to a recent systematic review including 28 studies with cancer patients, existing evidence indicates that cancer-related pain management with the use of opioids is associated with poor overall survival (OS) in advanced cancer patients (but not progression-free survival, PFS). Postoperative analgesia had poor effect on PFS (but not OS) and intraoperative opioids use was not demonstrated to be associated with survival. ${ }^{123}$ An interesting conclusion was presented in a secondary analysis of a prospective study including 1404 patients with advanced cancer. ${ }^{124}$ This study demonstrated association between opioid use and decreased survival; however, the relationship weakened in a subgroup analysis adjusting for $\mathrm{C}$-reactive protein. The authors raise an interesting hypothesis that survival in these patients may be partly related to tumor-related inflammation causing increased pain and the need to administer opioids. ${ }^{124}$ Tumor-related inflammation is a factor associated with cancer cachexia, which by itself can influence prognosis and survival. ${ }^{129,130}$

Interesting results were also obtained in a secondary analysis of data from two RCTs in advanced cancer patients with opioid-induced constipation treated with the opioid antagonist MNTX. A significant increase in overall survival was found in these patients compared to the placebo group. ${ }^{131}$ Assessing patient survival was not a primary aim of the study, however, which limits its significance.

The risk of developing cancer and cancer mortality was evaluated in a prospective manner in over 13,000 individuals with chronic non-cancer pain followed for up to 10 years. No difference in the risk of developing cancer and cancer mortality was found between long-term opioid users and individuals without chronic pain. ${ }^{132}$ When interpreting this data, one has to consider the long timeline of cancer development. Ten years of observation, however 
long, may not be sufficient to assess the full risk. Further epidemiological prospective long-term trials in individuals with chronic non-malignant pain are needed.

\section{Infections}

Another potential consequence of opioid-related immunosuppression includes increased susceptibility to infections. Increased risk of these serious complications has been revealed in a number of epidemiological studies. ${ }^{23,24,133-135}$ For example, opioid use was associated with a $38 \%$ higher risk of community-acquired pneumonia and a more than $60 \%$ increased risk of invasive pneumococcal diseases. ${ }^{23,133}$ In a study of patients with rheumatoid arthritis, serious infections necessitating hospital admission appeared 40\% more often during periods of current opioid use compared to periods of non-use. ${ }^{134}$ The incidence rate of infections in these studies was higher when long-acting opioids with stronger immunosuppressive properties were used in higher doses. $^{23,24,133,134}$ Interestingly, the risk was the highest during the first 2 to 4 weeks of treatment. ${ }^{23,24}$ A higher risk of developing infection was also demonstrated in a retrospective study with cancer patients taking morphine as compared to individuals treated with oxycodone, the latter being associated with lower immunosuppressive properties. ${ }^{136}$ In another study done in a cancer population, the risk for developing infections did not differ among different opioids (morphine, fentanyl and oxycodone) used but was correlated with increased dose $(10 \mathrm{mg}$ elevation of MEDD was associated with the increase in risk of infection by $2 \%)^{137}$

Opioid use (predominantly non-medical use) is frequent in HIV-infected patients. Based on experimental studies, it appears that mu opioid agonists may potentiate HIV replication. ${ }^{135,138,139}$ In accordance with these investigations a human report performed in 200 subjects divided into four groups depending on HIV + or HIV - status and the use of opioids demonstrated that opioid use was associated with higher viral load and lower CD4+ T cell count. $^{140}$

\section{Cardiovascular Complications}

Opioid peptides and opioid receptors are implicated in modulation of electrophysiological function, heart rate and vascular function and play a role in pathophysiology of cardiovascular (CV) diseases. ${ }^{141}$ Secondary to vasodilatation and reduction of cardiac output, opioids may cause hypotension, orthostatic hypotension, pulmonary edema and syncope. Opioids can also produce sinus bradycardia, supraventricular tachycardia and atrial fibrillation, may impair atrioventricular conduction, and prolong the QT interval, with the risk of torsades de pointes. The highest risk of the latter is known to occur with methadone use. ${ }^{15}$ All these actions are mediated by activation of peripheral opioid receptors as well as opioid-independent mechanisms (including histamine release mediated by morphine). Importantly, opioids may also affect the efficacy of drugs used in the treatment of $\mathrm{CV}$ diseases. For example, morphine was shown to decrease serum concentration of oral P2Y12 inhibitors, such as clopidogrel and ticlopidine. ${ }^{142}$ The mechanism of this interaction seems to be related to the delay in gastric emptying and decreased absorption of antiplatelet agents. Opioids may enhance the hypotensive effect of antihypertensive drugs.

A number of observational and experimental studies that have raised concerns regarding the safety of opioids in $\mathrm{CV}$ diseases have been published. For example, in a nested case-control study that included over 11,500 patients with myocardial infarction (MI), the current use of opioids was associated with a $28 \%$ increased risk for MI compared with non-use. ${ }^{16}$ The risk was highest for people treated with morphine and meperidine. Individuals with cancer and major risk factors for MI were excluded from the study. In a cohort study involving almost 150,000 individuals receiving opioids for chronic pain for $>180$ days and over 120,000 users of cyclooxygenase- 2 inhibitors, the risk of MI was determined to be 2.7 and 1.7-1.9 times higher in these two groups of patients, respectively, compared with the general population. ${ }^{143}$ Higher doses of opioids were associated with a higher risk. Patients with a history of MI or coronary revascularization and with a diagnosis of cancer were excluded from this analysis.

An interesting observation was done in a cohort study comparing safety of opioids, COX2-inhibitors and nonselective non-steroidal anti-inflammatory drugs (NSAIDs) in older individuals (mean age 80) who initiated the use of analgesics. Compared with nonselective NSAIDs, the use of opioids increased the risk of all $\mathrm{CV}$ events by $77 \%$, the risk of heart failure increased by $63 \%$, the risk of MI more than doubled and out-of-hospital cardiac deaths were nearly twice the risk induced by NSAIDS. ${ }^{25}$ Importantly, the risk of CV events in patients using opioids exceeded the risk in individuals receiving COX-2 inhibitors in this sample. In a retrospective cohort study including approximately 23,000 patients (mean age 48), the use of long-acting opioids was associated with a $65 \%$ increase in the risk 
of $\mathrm{CV}$ death as compared to analgesic anticonvulsants or low doses of cyclic antidepressants. ${ }^{26}$

\section{Influence on Sleep Quality and Sleep-Disordered Breathing}

On the contrary to common beliefs that opioids improve sleep, studies demonstrate, however, that opioid treatment can impair sleep quality and sleep architecture as well as contribute to daytime fatigue and sleepiness. Opioids can curtail total sleep length and sleep cycle length. Patients may wake more often and their stage N2 non-rapid eye movement sleep (light sleep) and transitions to wakefulness can be lengthened, whereas stage N3 (deep sleep) and the rapid eye movement stages can be shortened. ${ }^{144,145}$ Because of the suppressive effect on respiratory rate and tidal volume, as well as hypoxic and hypercapnic respiratory drive, opioid use may lead to a spectrum of respiratory derangements during sleep, including hypoventilation, hypoxemia, irregular breathing and apnea. Opioid use may induce sleep-disordered breathing (SDB), mostly of the central type, because of the influence of opioids on breathing rhythm and control of ventilation. ${ }^{17,18,146-149}$ Opioids can also trigger or exacerbate obstructive sleep apnea in predisposed individuals by causing relaxation of pharyngeal tone and increasing the collapsibility of the airways. ${ }^{17,146,147}$ Studies included in two systematic reviews demonstrated high prevalence of SDB and central sleep apnea (CSA) in patients using opioids for chronic pain, ranging from $75 \%$ to $91 \%$, and $18 \%$ to $33 \%$, respectively. ${ }^{18,146}$ The risk of CSA was demonstrated to be higher in patients with lower body mass, when the dose of oral opioid $\geq 200$ MEDD and opioids were combined with benzodiazepines or other CNS depressant agents. ${ }^{17,146,148}$ Significant sleep disturbances were also demonstrated in an observational investigation in patients with advanced cancer (84\%). ${ }^{147}$ Sleep apnea may contribute to arrhythmias, myocardial infarction, stroke and increased mortality. ${ }^{17,26,146,150-152}$

\section{Opioid-Induced Bowel Dysfunction}

Opioids affect bowel function through binding to peripheral opioid receptors spread throughout the gastrointestinal (GI) tract. Constipation occur in above $40 \%$ of individuals using opioids, and GI pseudo-obstruction may develop as a serious consequence. ${ }^{5,6,19,20,153,154}$ In a cohort of elderly patients, the hazard ratio of developing bowel obstruction in individuals prescribed opioids for chronic pain compared to those who used nonselective NSAIDs exceeded $4 .{ }^{25}$ A variant of opioid-induced bowel dysfunction is narcotic bowel syndrome (NBS). ${ }^{155-159}$ Patients receiving opioids for the treatment of pain actually become more sensitive to painful stimuli and experience worsened abdominal pain with escalating opioid doses and improvement after cessation of opioids. The underlying pathophysiology of this syndrome is not fully understood. In parallel to other functional GI disorders, it may result from increased segmental motility and opioid-induced hyperalgesia. $^{20,158,159}$ The real prevalence of NBS is not known and the syndrome is likely to be unrecognized. ${ }^{156-158}$

A newer but significant concept concerns the influence of a persistent opioid-induced decrease in gastrointestinal motility on the bowel microbiome. ${ }^{160-165}$ Opioid-induced changes in the gut microbiome include considerable reduction of the microbiota and a significant increase in pathogenic communities of bacteria, as well as significant impairment of bile acids and morphine (and some other opioids) metabolism in the gut. ${ }^{160-162,166}$ Usually, considerable amounts of morphine glucuronides are converted by bowel bacteria back to morphine and reabsorbed to the circulation (enterohepatic circulation). ${ }^{167}$ Disturbance of this mechanism may at least partly explain the development of tolerance to opioids, as a considerable amount of the dose of morphine applied is lost with faeces and not reabsorbed. ${ }^{161}$ Moreover, changes in the microbiome and intestinal epithelial integrity and function caused by opioids increase the permeability of the gut barrier and promote bacterial translocation to the tissues and release of inflammatory mediators. ${ }^{97,168}$ The inflammatory processes induced by opioids may lead to modulation of the anti-nociceptive responses to these drugs. ${ }^{160,161,163,169}$ Clinical evidence for both of these mechanisms are still lacking.

\section{Risk of Unintentional Opioid Overdose and Increased Mortality}

Evidence shows that non-medical use of opioids is associated with increased risk of all-cause mortality and overdose death. ${ }^{170}$ According to a systematic review, mortality risk in individuals taking opioids for chronic pain relative to populations with similar clinical characteristics not prescribed opioids cannot be definitively estimated at present because of methodological 
limitations of published studies ${ }^{27}$ However, a number of individual epidemiological investigations published so far indicated that patients treated with opioids for chronic pain may be susceptible to a higher risk of injuries, poisoning and mortality. ${ }^{25,26,132,171-180}$ For example, in a trial concerning approximately 10,000 patients with chronic non-malignant pain treated with opioids, 51 cases of opioid overdose, including 6 (12\%) opioidrelated deaths, were identified. Patients receiving $\geq 100 \mathrm{mg}$ of MEDD had a $1.8 \%$ annual overdose rate. ${ }^{171}$ Another interesting study showed a $90 \%$ increased risk of out-of-hospital deaths associated with the use of both low and high doses of long-acting opioids as compared to antiepileptics and low-dose antidepressants. The risk in less than one-third of the cases was related to opioid overdose, and the most frequent cause of non-overdose deaths were $\mathrm{CV}$ events. ${ }^{26}$ The risk of increased out-ofhospital mortality was higher in patients using morphine and fentanyl than in those using oxycodone in another cohort study of the same group. ${ }^{175}$ Importantly, opioids (including tramadol) were demonstrated to cause higher risk of mortality among patients treated for chronic nonmalignant pain than NSAIDs. ${ }^{25,176}$ The risk of opioidrelated death may be increased with the use of longacting opioids, at a higher dose range, within 4 weeks after opioid initiation. The concomitant use of gabapentin, benzodiazepines, antidepressants and antipsychotics further increases the risk. Men are more susceptible to these complications, especially those with a history of alcohol abuse, than women. Finally, the prescription of opioids by more than one physician and having them dispensed by more than one pharmacy are predictors of toxicity and the risk of mortality. ${ }^{26,132,171-174,179,180}$

\section{Discussion}

Increasing the access to effective and safe analgesia is a priority in view of unmet needs and common undertreatment of pain around the world. ${ }^{181,182}$ Opioids are the most important drugs in the treatment of severe pain.

The present review shows that this therapy may be, however, associated with numerous of potentially serious adverse effects, which may in fact already have occurred early in the treatment. Some complications may develop insidiously and remain undetected or be erroneously attributed to underlying chronic disease or other causes. However, what appears important is that the level of risk may depend on the type of opioid, the dose used, time since opioid initiation, and the formulation. For example, buprenorphine was demonstrated to pose a lower risk of hypogonadism and immunosuppression compared to other opioids. ${ }^{52-54,86,91,92}$ Thus, if these observations are confirmed in future studies, this drug may be chosen whenever it provides adequate analgesia. Opioids differ in the affinities to opioid receptors and some of them posses additional non-opioid mechanism of action, such as, for example, methadone which blocks NMDA receptors or tapentadol that inhibits reuptake of norepinephrine. These differences may underlie the diversities of opioid adverse effects; however, this issue is poorly investigated. The highest risk of some of potential consequences of opioid treatment, such as fracture and mortality, was associated with the use of higher doses of opioids within 2-4 weeks following their implementation. Pain therapy can be optimized by keeping the dose of an opioid as low as possible when using multi-modal treatment with close monitoring, particularly in the period of opioid titration. Further studies focusing on specific opioids used in different dose ranges and types of formulations may guide future strategies in opioid treatment.

Most, if not all, complications of opioid therapy presented in this review have complex pathophysiology, and multiple confounding factors make the results difficult to interpret. Pain itself can, for example, inhibit the immune system and be associated with shorter survival. $28,30,123$ Patients with serious life-limiting diseases may already be immunosuppressed, which may be further aggravated by the frequent use of corticosteroids and other immunosuppressive medications. ${ }^{3,13,183}$ Using corticosteroids or metoclopramide may also cause hypogonadism. ${ }^{184,185}$ Patients may use other CNS depressants associated with an increased risk of fallrelated fractures (for example, antipsychotic agents, benzodiazepines and antidepressants). ${ }^{186-188}$

\section{Study Limitations}

The present article was based on a comprehensive literature review. The included studies have different limitations and need to be interpreted cautiously. Many of them were uncontrolled trials and retrospective in nature. Some of them were not designed to assess the adverse effect of opioids as a primary goal. Knowledge of the immunosuppressive and cancer-promoting effects of opioids as well as changes in the bowel microbiome has been derived mostly from animal studies, and studies in humans are so far lacking. The most widely studied drug is morphine, and a smaller percentage of data concerned other opioids, which may differ in their mechanism of action and effects.

Human experimental studies included a small number of patients and multiple additional factors contributed to 
their results, so they cannot be considered conclusive as yet. The presence of cancer was an exclusion criterion in cohort epidemiological studies assessing adverse effects such as, for example, the risk of $\mathrm{CV}$ events, which is why these data cannot be directly related to patients with cancer, who mostly need long-term opioid therapy. Epidemiological investigations with populations treated with opioids were also related to certain regions and countries of the world and cannot be directly extrapolated to others. Most studies demonstrating high risk of mortality were performed in North America.

\section{Conclusions}

Three important conclusions can be drawn at the moment. First, long-term use of opioids increases the risk of drug-related events and may cause serious adverse effects in a significant number of patients. However, we need many more studies in humans to assess the risk associated with the use of a specific opioid analgesic and its clinical significance. Second, the risk of adverse effects of long-term therapy needs to be taken into consideration when pain is treated with opioids. Health care providers and pharmacists should discuss them with patients, prevent complications, if possible, and ensure timely diagnosis and adequate management. Third, future strategies for the treatment of chronic pain need to develop adequate methods to minimize adverse effects of opioids, including dose reduction, discontinuation and switching to opioid and nonopioid alternative analgesics in order to guide physicians' decisions about treatment and provide patients with optimal care.

\section{Disclosure}

The authors declare no conflicts of interest.

\section{References}

1. Chou R, Turner JA, Devine EB, et al. The effectiveness and risks of long-term opioid therapy for chronic pain: a systematic review for a National Institutes of Health Pathways to Prevention Workshop. Ann Intern Med. 2015;162(4):276. doi:10.7326/M14-2559

2. Carmona-Bayonas A, Jiménez-Fonseca P, Castañón E, et al. Chronic opioid therapy in long-term cancer survivors. Clin Transl Oncol. 2017;19(2):236-250. doi:10.1007/s12094-016-1529-6

3. Fountas A, Van Uum S, Karavitaki N. Opioid-induced endocrinopathies. Lancet Diabetes Endocrinol. 2020;8(1):68-80. doi:10.1016/S2213-8587(19)30254-2

4. Hochberg U, Ojeda A, Brill S, Perez J. An internet-based survey to assess clinicians' knowledge and attitudes towards opioid-induced hypogonadism. Pain Pract. 2019;19(2):176-182. doi:10.1111/ papr.12731
5. Corli O, Santucci C, Corsi N, Radrezza S, Galli F, Bosetti C. The burden of opioid adverse events and the influence on cancer patients' symptomatology. J Pain Symptom Manage. 2019;57 (5):899-908. doi:10.1016/j.jpainsymman.2019.02.009

6. Oosten AW, Oldenmenger WH, Mathijssen RHJ, van der Rijt CCD. A systematic review of prospective studies reporting adverse events of commonly used opioids for cancer-related pain: a call for the use of standardized outcome measures. J Pain. 2015;16(10):935-946. doi:10.1016/j.jpain.2015.05.006

7. Abuse NI on D. Opioid overdose crisis. national institute on drug abuse; 2021. Available from: https://www.drugabuse.gov/drugtopics/opioids/opioid-overdose-crisis. Accessed February 22, 2021.

8. Vadivelu N, Kai AM, Kodumudi V, Sramcik J, Kaye AD. The opioid crisis: a comprehensive overview. Curr Pain Headache Rep. 2018;22(3):16. doi:10.1007/s11916-018-0670-z

9. Zimmer Z, Zajacova A, Grol-Prokopczyk H. Trends in pain prevalence among adults aged 50 and older across Europe, 2004 to 2015. J Aging Health. 2020;32(10):1419-1432. doi:10.1177/ 0898264320931665

10. Birthi P, Nagar VR, Nickerson R, Sloan PA. Hypogonadism associated with long-term opioid therapy: a systematic review. $J$ Opioid Manag. 2015;11(3):255-278. doi:10.5055/ jom.2015.0274

11. Wersocki E, Bedson J, Chen Y, LeResche L, Dunn KM. Comprehensive systematic review of long-term opioids in women with chronic noncancer pain and associated reproductive dysfunction (hypothalamic-pituitary-gonadal axis disruption). Pain. 2017;158(1):8-16. doi:10.1097/j.pain.0000000000000691

12. Bawor M, Bami H, Dennis BB, et al. Testosterone suppression in opioid users: a systematic review and meta-analysis. Drug Alcohol Depend. 2015;149:1-9. doi:10.1016/j. drugalcdep.2015.01.038

13. McWilliams K, Simmons C, Laird BJ, Fallon MT. A systematic review of opioid effects on the hypogonadal axis of cancer patients. Support Care Cancer. 2014;22(6):1699-1704. doi:10.1007/s00520-014-2195-2

14. Boland JW, McWilliams K, Ahmedzai SH, Pockley AG. Effects of opioids on immunologic parameters that are relevant to anti-tumour immune potential in patients with cancer: a systematic literature review. Br J Cancer. 2014;111 (5):866-873. doi:10.1038/bjc.2014.384

15. Behzadi M, Joukar S, Beik A. Opioids and cardiac arrhythmia: a literature review. Med Princ Pract. 2018;27(5):401-414. doi: $10.1159 / 000492616$

16. Li L, Setoguchi S, Cabral H, Jick S. Opioid use for noncancer pain and risk of myocardial infarction amongst adults. $J$ Intern Med. 2013;273(5):511-526. doi:10.1111/joim.12035

17. Filiatrault M-L, Chauny J-M, Daoust R, Roy M-P, Denis R, Lavigne G. Medium increased risk for central sleep apnea but not obstructive sleep apnea in long-term opioid users: a systematic review and meta-analysis. $J$ Clin Sleep Med. 2016;12(4):617-625. doi:10.5664/jcsm.5704

18. Mubashir T, Nagappa M, Esfahanian N, et al. Prevalence of sleep-disordered breathing in opioid users with chronic pain: a systematic review and meta-analysis. $J$ Clin Sleep Med. 2020;16(6):961-969. doi:10.5664/jcsm.8392

19. Bell TJ, Panchal SJ, Miaskowski C, Bolge SC, Milanova T, Williamson R. The prevalence, severity, and impact of opioid-induced bowel dysfunction: results of a US and European Patient Survey (PROBE 1). Pain Med. 2009;10 (1):35-42. doi:10.1111/j.1526-4637.2008.00495.x

20. Camilleri M, Lembo A, Katzka DA. Opioids in gastroenterology: treating adverse effects and creating therapeutic benefits. Clin Gastroenterol Hepatol. 2017;15(9):1338-1349. doi:10.1016/j. cgh.2017.05.014 
21. Miller M, Stürmer T, Azrael D, Levin R, Solomon DH. Opioid analgesics and the risk of fractures in older adults with arthritis. $J$ Am Geriatr Soc. 2011;59(3):430-438. doi:10.1111/j.15325415.2011.03318.x

22. Yue Q, Ma Y, Teng Y, et al. An updated analysis of opioids increasing the risk of fractures. PLoS One. 2020;15. doi:10.1371/journal.pone. 0220216

23. Dublin S, Walker RL, Jackson ML, et al. Use of opioids or benzodiazepines and risk of pneumonia in older adults: a population-based case-control study. J Am Geriatr Soc. 2011;59 (10):1899-1907. doi:10.1111/j.1532-5415.2011.03586.x

24. Wiese AD, Griffin MR, Schaffner W, et al. Long-acting opioid use and the risk of serious infections: a retrospective cohort study. Clin Infect Dis. 2019;68(11):1862-1869. doi:10.1093/cid/ciy809

25. Solomon DH, Rassen JA, Glynn RJ, Lee J, Levin R, Schneeweiss S. The comparative safety of analgesics in older adults with arthritis. Arch Intern Med. 2010;170(22):1968-1976. doi:10.1001/archinternmed.2010.391

26. Ray WA, Chung CP, Murray KT, Hall K, Stein CM. Prescription of long-acting opioids and mortality in patients with chronic noncancer pain. JAMA. 2016;315(22):2415-2423. doi:10.1001/ jama.2016.7789

27. Larney S, Peacock A, Tran LT, et al. All-cause and overdose mortality risk among people prescribed opioids: a systematic review and meta-analysis. Pain Med. 2020;21(12):3700-3711. doi:10.1093/pm/pnaa214

28. Novy DM, Nelson DV, Koyyalagunta D, Cata JP, Gupta P, Gupta K. Pain, opioid therapy, and survival: a needed discussion. Pain. 2020;161(3):496-501. doi:10.1097/j. pain. 0000000000001736

29. Nguyen J, Luk K, Vang D, et al. Morphine stimulates cancer progression and mast cell activation and impairs survival in transgenic mice with breast cancer. Br J Anaesth. 2014;113 (Suppl 1):S4-S13. doi:10.1093/bja/aeu090

30. Boland JW, Pockley AG. Influence of opioids on immune function in patients with cancer pain: from bench to bedside. $\mathrm{Br}$ J Pharmacol. 2018;175(14):2726-2736. doi:10.1111/bph.13903

31. O'Rourke TK, Wosnitzer MS. Opioid-Induced Androgen Deficiency (OPIAD): diagnosis, management, and literature review. Curr Urol Rep. 2016;17(10):76. doi:10.1007/s11934016-0634-y

32. Rhodin A, Stridsberg M, Gordh T. Opioid endocrinopathy: a clinical problem in patients with chronic pain and long-term oral opioid treatment. Clin J Pain. 2010;26(5):374-380. doi:10.1097/AJP.0b013e3181d1059d

33. Antony T, Alzaharani SY, El-Ghaiesh SH. Opioid-induced hypogonadism: pathophysiology, clinical and therapeutics review. Clin Exp Pharmacol Physiol. 2020;47(5):741-750. doi:10.1111/14401681.13246

34. Deepinder F, Braunstein GD. Drug-induced gynecomastia: an evidence-based review. Expert Opin Drug Saf. 2012;11 (5):779-795. doi:10.1517/14740338.2012.712109

35. Strasser F, Palmer JL, Schover LR, et al. The impact of hypogonadism and autonomic dysfunction on fatigue, emotional function, and sexual desire in male patients with advanced cancer: a pilot study. Cancer. 2006;107(12):2949-2957. doi:10.1002/ cncr.22339

36. Katz N, Mazer NA. The impact of opioids on the endocrine system. Clin J Pain. 2009;25(2):170-175. doi:10.1097/ AJP.0b013e3181850df6

37. Coluzzi F, Billeci D, Maggi M, Corona G. Testosterone deficiency in non-cancer opioid-treated patients. $J$ Endocrinol Invest. 2018;41(12):1377-1388. doi:10.1007/s40618-018-0964-3

38. Zylicz Z. Opioid-induced hypogonadism: the role of androgens in the well-being and pain thresholds in men and women with advanced disease. Adv Pall Med. 2009;8:57-62.
39. Marudhai S, Patel M, Valaiyaduppu Subas S, et al. Long-term opioids linked to hypogonadism and the role of testosterone supplementation therapy. Cureus. 2020. Available from https:// www.ncbi.nlm.nih.gov/pmc/articles/PMC7645309.

40. Stoffel EC, Ulibarri CM, Folk JE, Rice KC, Craft RM. Gonadal hormone modulation of mu, kappa, and delta opioid antinociception in male and female rats. J Pain. 2005;6(4):261-274. doi:10.1016/j.jpain.2004.12.006

41. Duarte RV, Raphael JH, Southall JL, Labib MH, Whallett AJ, Ashford RL. Hypogonadism and low bone mineral density in patients on long-term intrathecal opioid delivery therapy. $B M J$ Open. 2013;3(6):e002856. doi:10.1136/bmjopen-2013-002856

42. Mendelson JH, Mendelson JE, Patch VD. Plasma testosterone levels in heroin addiction and during methadone maintenance. J Pharmacol Exp Ther. 1975;192(1):211-217.

43. Azizi F, Vagenakis AG, Longcope C, Ingbar SH, Braverman LE. Decreased serum testosterone concentration in male heroin and methadone addicts. Steroids. 1973;22(4):467-472. doi:10.1016/ 0039-128X(73)90002-0

44. Daniell HW. Opioid endocrinopathy in women consuming prescribed sustained-action opioids for control of nonmalignant pain. J Pain. 2008;9(1):28-36. doi:10.1016/j.jpain.2007.08.005

45. Richardson E, Bedson J, Chen Y, Lacey R, Dunn KM. Increased risk of reproductive dysfunction in women prescribed long-term opioids for musculoskeletal pain: a matched cohort study in the Clinical Practice Research Datalink. Eur J Pain. 2018;22 (9):1701-1708. doi:10.1002/ejp.1256

46. Valverde-Filho J, da Cunha Neto MBC, Fonoff ET, de Meirelles ES, Teixeira MJ. Chronic spinal and oral morphine-induced neuroendocrine and metabolic changes in noncancer pain patients. Pain Med. 2015;16(4):715-725. doi:10.1111/pme.12661

47. Rubinstein A, Carpenter DM. Elucidating risk factors for androgen deficiency associated with daily opioid use. Am J Med. 2014;127(12):1195-1201. doi:10.1016/j.amjmed.2014.07.015

48. Abs R, Verhelst J, Maeyaert J, et al. Endocrine consequences of long-term intrathecal administration of opioids. J Clin Endocrinol Metab. 2000;85(6):2215-2222. doi:10.1210/jcem.85.6.6615

49. Rajagopal A, Vassilopoulou-Sellin R, Palmer JL, Kaur G, Bruera E. Symptomatic hypogonadism in male survivors of cancer with chronic exposure to opioids. Cancer. 2004;100 (4):851-858. doi:10.1002/cncr.20028

50. Merdin A, Merdin FA, Gündüz Ş, Bozcuk H, Coşkun HŞ. Opioid endocrinopathy: a clinical problem in patients with cancer pain. Exp Ther Med. 2016;11(5):1819-1822. doi:10.3892/etm.2016.3156

51. Rubinstein AL, Carpenter DM. Association between commonly prescribed opioids and androgen deficiency in men: a retrospective cohort analysis. Pain Med. 2017;18(4):637-644. doi:10.1093/pm/pnw182

52. Aurilio C, Ceccarelli I, Pota V, et al. Endocrine and behavioural effects of transdermal buprenorphine in pain-suffering women of different reproductive ages. Endocr J. 2011;58(12):1071-1078. doi:10.1507/endocrj.EJ11-0095

53. Bliesener N, Albrecht S, Schwager A, Weckbecker K, Lichtermann D, Klingmüller D. Plasma testosterone and sexual function in men receiving buprenorphine maintenance for opioid dependence. J Clin Endocrinol Metab. 2005;90(1):203-206. doi:10.1210/jc.2004-0929

54. Hallinan R, Byrne A, Agho K, McMahon CG, Tynan P, Attia J. Hypogonadism in men receiving methadone and buprenorphine maintenance treatment. Int $J$ Androl. 2009;32(2):131-139. doi:10.1111/j.1365-2605.2007.00824.x

55. Baron R, Jansen J-P, Binder A, et al. Tolerability, safety, and quality of life with tapentadol prolonged release (PR) compared with oxycodone/naloxone PR in patients with severe chronic low back pain with a neuropathic component: a randomized, controlled, open-label, phase 3b/4 trial. Pain Pract. 2016;16(5):600-619. doi:10.1111/papr.12361 
56. Daniell HW. Hypogonadism in men consuming sustained-action oral opioids. J Pain. 2002;3(5):377-384. doi:10.1054/ jpai.2002.126790

57. Rubinstein AL, Carpenter DM, Minkoff JR. Hypogonadism in men with chronic pain linked to the use of long-acting rather than short-acting opioids. Clin J Pain. 2013;29(10):840-845. doi:10.1097/AJP.0b013e31827c7b5d

58. Fraser L-A, Morrison D, Morley-Forster P, et al. Oral opioids for chronic non-cancer pain: higher prevalence of hypogonadism in men than in women. Exp Clin Endocrinol Diabetes. 2009;117 (1):38-43. doi:10.1055/s-2008-1076715

59. Jasuja GK, Ameli O, Reisman JI, et al. Health outcomes among long-term opioid users with testosterone prescription in the veterans health administration. JAMA Netw Open. 2019;2(12): e1917141. doi:10.1001/jamanetworkopen.2019.17141

60. Basaria S, Travison TG, Alford D, et al. Effects of testosterone replacement in men with opioid-induced androgen deficiency: a randomized controlled trial. Pain. 2015;156(2):280-288. doi:10.1097/01.j.pain.0000460308.86819.aa

61. AminiLari M, Manjoo P, Craigie S, Couban R, Wang L, Busse JW. Hormone replacement therapy and opioid tapering for opioid-induced hypogonadism among patients with chronic noncancer pain: a systematic review. Pain Med. 2019;20 (2):301-313. doi:10.1093/pm/pny040

62. Donegan D, Bancos I. Opioid-induced adrenal insufficiency. Mayo Clin Proc. 2018;93(7):937-944. doi:10.1016/j. mayocp.2018.04.010

63. Lamprecht A, Sorbello J, Jang C, Torpy DJ, Inder WJ. Secondary adrenal insufficiency and pituitary dysfunction in oral/transdermal opioid users with non-cancer pain. Eur J Endocrinol. 2018;179 (6):353-362. doi:10.1530/EJE-18-0530

64. Gibb FW, Stewart A, Walker BR, Strachan MWJ. Adrenal insufficiency in patients on long-term opioid analgesia. Clin Endocrinol (Oxf). 2016;85(6):831-835. doi:10.1111/cen.13125

65. Policola C, Stokes V, Karavitaki N, Grossman A. Adrenal insufficiency in acute oral opiate therapy. Endocrinol Diabetes Metab Case Rep. 2014;2014:130071. doi:10.1530/EDM-13-0071

66. Oltmanns KM, Fehm HL, Peters A. Chronic fentanyl application induces adrenocortical insufficiency. $J$ Intern Med. 2005;257 (5):478-480. doi:10.1111/j.1365-2796.2005.01483.x

67. Müssig K, Knaus-Dittmann D, Schmidt H, Mörike K, Häring H-U. Secondary adrenal failure and secondary amenorrhoea following hydromorphone treatment. Clin Endocrinol (Oxf). 2007;66(4):604-605. doi:10.1111/j.13652265.2007.02779.x

68. Napier C, Gan EH, Pearce SHS. Loperamide-induced hypopituitarism. BMJ Case Rep. 2016;bcr2016216384. doi:10.1136/bcr-2016-216384

69. Debono M, Chan S, Rolfe C, Jones TH. Tramadol-induced adrenal insufficiency. Eur J Clin Pharmacol. 2011;67(8):865-867. doi:10.1007/s00228-011-0992-9

70. Nenke MA, Haylock CL, Rankin W, et al. Low-dose hydrocortisone replacement improves wellbeing and pain tolerance in chronic pain patients with opioid-induced hypocortisolemic responses. A pilot randomized, placebo-controlled trial. Psychoneuroendocrinology. 2015;56:157-167. doi:10.1016/j. psyneuen.2015.03.015

71. Vuong C, Van Uum SHM, O'Dell LE, Lutfy K, Friedman TC. The effects of opioids and opioid analogs on animal and human endocrine systems. Endocr Rev. 2010;31(1):98-132. doi:10.1210/ er.2009-0009

72. Coluzzi F, Pergolizzi J, Raffa RB, Mattia C. The unsolved case of 'bone-impairing analgesics': the endocrine effects of opioids on bone metabolism. Ther Clin Risk Manag. 2015;11:515-523. doi:10.2147/TCRM.S79409
73. Kinjo M, Setoguchi S, Schneeweiss S, Solomon DH. Bone mineral density in subjects using central nervous system-active medications. Am J Med. 2005;118(12):1414. doi:10.1016/j. amjmed.2005.07.033

74. Nelson RE, Nebeker JR, Sauer BC, LaFleur J. Factors associated with screening or treatment initiation among male United States veterans at risk for osteoporosis fracture. Bone. 2012;50 (4):983-988. doi:10.1016/j.bone.2011.11.014

75. Rolita L, Spegman A, Tang X, Cronstein BN. Greater number of narcotic analgesic prescriptions for osteoarthritis is associated with falls and fractures in elderly adults. $J$ Am Geriatr Soc. 2013;61(3):335-340. doi:10.1111/jgs. 12148

76. Vestergaard P, Rejnmark L, Mosekilde L. Fracture risk associated with the use of morphine and opiates. J Intern Med. 2006;260 (1):76-87. doi:10.1111/j.1365-2796.2006.01667.x

77. Li L, Setoguchi S, Cabral H, Jick S. Opioid use for noncancer pain and risk of fracture in adults: a nested case-control study using the general practice research database. Am J Epidemiol. 2013;178(4):559-569. doi:10.1093/aje/kwt013

78. Acurcio FA, Moura CS, Bernatsky S, Bessette L, Rahme E. Opioid use and risk of nonvertebral fractures in adults with rheumatoid arthritis: a nested case-control study using administrative databases. Arthritis Rheumatol. 2016;68(1):83-91. doi:10.1002/art.39422

79. Sacerdote P. Opioid-induced immunosuppression. Curr Opin Support Palliat Care. 2008;2(1):14-18. doi:10.1097/ SPC.0b013e3282f5272e

80. Sacerdote P. Opioids and the immune system. Palliat Med. 2006;20(Suppl 1):S9-S15. doi:10.1191/0269216306pm1124oa

81. Liang X, Liu R, Chen C, Ji F, Li T. Opioid system modulates the immune function: a review. Transl Perioper Pain Med. 2016;1 (1):5-13.

82. Franchi S, Moschetti G, Amodeo G, Sacerdote P. Do all opioid drugs share the same immunomodulatory properties? A review from animal and human studies. Front Immunol. 2019;10:2914. doi:10.3389/fimmu.2019.02914

83. Yardeni IZ, Beilin B, Mayburd E, Alcalay Y, Bessler H. Relationship between fentanyl dosage and immune function in the postoperative period. J Opioid Manag. 2008;4(1):27-33. doi:10.5055/jom.2008.0005

84. Beilin B, Shavit Y, Hart J, et al. Effects of anesthesia based on large versus small doses of fentanyl on natural killer cell cytotoxicity in the perioperative period. Anesth Analg. 1996;82 (3):492-497. doi:10.1097/00000539-199603000-00011

85. Yeager MP, Colacchio TA, Yu CT, et al. Morphine inhibits spontaneous and cytokine-enhanced natural killer cell cytotoxicity in volunteers. Anesthesiology. 1995;83(3):500-508. doi:10.1097/ 00000542-199509000-00008

86. Martucci C, Panerai AE, Sacerdote P. Chronic fentanyl or buprenorphine infusion in the mouse: similar analgesic profile but different effects on immune responses. Pain. 2004;110(12):385-392. doi:10.1016/j.pain.2004.04.020

87. Molina-Martínez LM, González-Espinosa C, Cruz SL. Dissociation of immunosuppressive and nociceptive effects of fentanyl, but not morphine, after repeated administration in mice: fentanyl-induced sensitization to LPS. Brain Behav Immun. 2014;42:60-64. doi:10.1016/j.bbi.2014.06.011

88. Yeager MP, Procopio MA, DeLeo JA, Arruda JL, Hildebrandt L, Howell AL. Intravenous fentanyl increases natural killer cell cytotoxicity and circulating CD16(+) lymphocytes in humans. Anesth Analg. 2002;94(1):94-99. doi:10.1213/00000539200201000-00018

89. Jacobs R, Karst M, Scheinichen D, et al. Effects of fentanyl on cellular immune functions in man. Int $J$ Immunopharmacol. 1999;21(7):445-454. doi:10.1016/S0192-0561(99)00025-9 
90. Sacerdote P, Manfredi B, Mantegazza P, Panerai AE. Antinociceptive and immunosuppressive effects of opiate drugs: a structure-related activity study. $\mathrm{Br} J$ Pharmacol. 1997;121 (4):834-840. doi:10.1038/sj.bjp.0701138

91. D'Elia M, Patenaude J, Hamelin C, Garrel DR, Bernier J. No detrimental effect from chronic exposure to buprenorphine on corticosteroid-binding globulin and corticosensitive immune parameters. Clin Immunol. 2003;109(2):179-187. doi:10.1016/ S1521-6616(03)00177-3

92. Filipczak-Bryniarska I, Nazimek K, Nowak B, Kozlowski M, Wąsik M, Bryniarski K. In contrast to morphine, buprenorphine enhances macrophage-induced humoral immunity and, as oxycodone, slightly suppresses the effector phase of cell-mediated immune response in mice. Int Immunopharmacol. 2018;54:344-353. doi:10.1016/j.intimp.2017.11.039

93. Sacerdote P, Bianchi M, Gaspani L, et al. The effects of tramadol and morphine on immune responses and pain after surgery in cancer patients. Anesth Analg. 2000;90(6):1411-1414. doi:10.1097/00000539-200006000-00028

94. Sacerdote P, Bianchi M, Manfredi B, Panerai AE. Effects of tramadol on immune responses and nociceptive thresholds in mice. Pain. 1997;72(3):325-330. doi:10.1016/S0304-3959(97) 00055-9

95. Gaspani L, Bianchi M, Limiroli E, Panerai AE, Sacerdote P. The analgesic drug tramadol prevents the effect of surgery on natural killer cell activity and metastatic colonization in rats. $J$ Neuroimmunol. 2002;129(1-2):18-24. doi:10.1016/S01655728(02)00165-0

96. Beilin B, Grinevich G, Yardeni IZ, Bessler H. Tramadol does not impair the phagocytic capacity of human peripheral blood cells. Can $J$ Anaesth. 2005;52(10):1035-1039. doi:10.1007/BF03021601

97. Szczepaniak A, Fichna J, Zielińska M. Opioids in cancer development, progression and metastasis: focus on colorectal cancer. Curr Treat Options Oncol. 2020;21. doi:10.1007/s11864-019-0699-1

98. Mathew B, Lennon FE, Siegler J, et al. The novel role of the mu opioid receptor in lung cancer progression: a laboratory investigation. Anesth Analg. 2011;112(3):558-567. doi:10.1213/ ANE.0b013e31820568af

99. Singleton PA, Lingen MW, Fekete MJ, Garcia JGN, Moss J. Methylnaltrexone inhibits opiate and VEGF-induced angiogenesis: role of receptor transactivation. Microvasc Res. 2006;72(12):3-11. doi:10.1016/j.mvr.2006.04.004

100. Friesen C, Roscher M, Alt A, Miltner E. Methadone, commonly used as maintenance medication for outpatient treatment of opioid dependence, kills leukemia cells and overcomes chemoresistance. Cancer Res. 2008;68(15):6059-6064. doi:10.1158/0008-5472.CAN-08-1227

101. Friesen C, Roscher M, Hormann I, et al. Cell death sensitization of leukemia cells by opioid receptor activation. Oncotarget. 2013;4(5):677-690. doi:10.18632/oncotarget.952

102. Friesen C, Hormann I, Roscher M, et al. Opioid receptor activation triggering downregulation of cAMP improves effectiveness of anti-cancer drugs in treatment of glioblastoma. Cell Cycle. 2014;13(10):1560-1570. doi:10.4161/cc.28493

103. Qin Y, Chen J, Li L, et al. Exogenous morphine inhibits human gastric cancer MGC- 803 cell growth by cell cycle arrest and apoptosis induction. Asian Pac J Cancer Prev. 2012;13 (4):1377-1382. doi:10.7314/APJCP.2012.13.4.1377

104. Tegeder I, Grösch S, Schmidtko A, et al. G protein-independent G1 cell cycle block and apoptosis with morphine in adenocarcinoma cells: involvement of p53 phosphorylation. Cancer Res. 2003;63(8):1846-1852.

105. Harimaya Y, Koizumi K, Andoh T, Nojima H, Kuraishi Y, Saiki I. Potential ability of morphine to inhibit the adhesion, invasion and metastasis of metastatic colon 26-L5 carcinoma cells. Cancer Lett. $\quad 2002 ; 187(1-2): 121-127 . \quad$ doi:10.1016/S0304-3835(02) 00360-9
106. He G, Li L, Guan E, Chen J, Qin Y, Xie Y. Fentanyl inhibits the progression of human gastric carcinoma MGC-803 cells by modulating NF- $\kappa \mathrm{B}-d e p e n d e n t$ gene expression in vivo. Oncol Lett. 2016;12(1):563-571. doi:10.3892/ol.2016.4619

107. Tian M, Jin L, Li R, Zhu S, Ji M, Li W. Comparison of oxycodone and morphine on the proliferation, apoptosis and expression of related molecules in the A549 human lung adenocarcinoma cell line. Exp Ther Med. 2016;12(2):559-566. doi:10.3892/ etm.2016.3346

108. Singleton PA, Mirzapoiazova T, Hasina R, Salgia R, Moss J. Increased $\mu$-opioid receptor expression in metastatic lung cancer. Br J Anaesth. 2014;113(Suppl 1):S103-S108. doi:10.1093/bja/ aeu 165

109. Zylla D, Gourley BL, Vang D, et al. Opioid requirement, opioid receptor expression, and clinical outcomes in patients with advanced prostate cancer. Cancer. 2013;119(23):4103-4110. doi:10.1002/cncr.28345

110. Zhang Y-F, Xu Q-X, Liao L-D, et al. Association of mu-opioid receptor expression with lymph node metastasis in esophageal squamous cell carcinoma. Dis Esophagus. 2015;28(2):196-203. doi:10.1111/dote. 12165

111. Yao Y, Yao R, Zhuang L, et al. MOR1 expression in gastric cancer: a biomarker associated with poor outcome. Clin Transl Sci. 2015;8(2):137-142. doi:10.1111/cts.12246

112. Bortsov AV, Millikan RC, Belfer I, Boortz-Marx RL, Arora H, McLean SA. $\mu$-opioid receptor gene A118G polymorphism predicts survival in patients with breast cancer. Anesthesiology. 2012;116(4):896-902. doi:10.1097/ALN.0b013e31824b96a1

113. Diaz-Cambronero O, Mazzinari G, Cata JP. Perioperative opioids and colorectal cancer recurrence: a systematic review of the literature. Pain Manag. 2018;8(5):353-361. doi:10.2217/pmt2018-0029

114. Sun Y, Li T, Gan TJ. The effects of perioperative regional anesthesia and analgesia on cancer recurrence and survival after oncology surgery: a systematic review and meta-analysis. Reg Anesth Pain Med. 2015;40(5):589-598. doi:10.1097/ AAP.0000000000000273

115. Wall T, Sherwin A, Ma D, Buggy DJ. Influence of perioperative anaesthetic and analgesic interventions on oncological outcomes: a narrative review. $B r \quad J$ Anaesth. 2019;123(2):135-150. doi:10.1016/j.bja.2019.04.062

116. Cata JP, Gottumukkala V, Thakar D, Keerty D, Gebhardt R, Liu DD. Effects of postoperative epidural analgesia on recurrence-free and overall survival in patients with nonsmall cell lung cancer. J Clin Anesth. 2014;26(1):3-17. doi:10.1016/j. jclinane.2013.06.007

117. Weng M, Chen W, Hou W, Li L, Ding M, Miao C. The effect of neuraxial anesthesia on cancer recurrence and survival after cancer surgery: an updated meta-analysis. Oncotarget. 2016;7 (12):15262-15273. doi:10.18632/oncotarget.7683

118. Zajączkowska R, Leppert W, Mika J, et al. Perioperative immunosuppression and risk of cancer progression: the impact of opioids on pain management. Pain Res Manag. 2018;2018:9293704. doi:10.1155/2018/9293704

119. Daley MD, Norman PH. Retrospective but not rigorous. Anesthesiology. 2009;111(1):203; author reply 203-204. doi:10.1097/ALN.0b013e3181a85e66

120. Das J, Kumar S, Khanna S, Mehta Y. Are we causing the recurrence-impact of perioperative period on long-term cancer prognosis: review of current evidence and practice. $J$ Anaesthesiol Clin Pharmacol. 2014;30(2):153-159. doi:10.4103/0970-9185.129996

121. Sessler DI, Pei L, Huang Y, et al. Recurrence of breast cancer after regional or general anaesthesia: a randomised controlled trial. Lancet. 2019;394(10211):1807-1815. doi:10.1016/S01406736(19)32313-X 
122. Boland J, Ziegler L, Boland E, Bennett M, Bennett MI. Is regular systemic opioid analgesia associated with shorter survival in adult patients with cancer? A systematic literature review. Pain. 2015;156(11):2152-2163. doi:10.1097/j.pain.0000000000000306

123. Zheng J, He J, Wang W, et al. The impact of pain and opioids use on survival in cancer patients: results from a population-based cohort study and a meta-analysis. Medicine (Baltimore). 2020;99 (9):e19306. doi:10.1097/MD.0000000000019306

124. Boland JW, Allgar V, Boland EG, et al. The relationship between pain, analgesics and survival in patients with advanced cancer; a secondary data analysis of the international European palliative care Cancer symptom study. Eur J Clin Pharmacol. 2020;76 (3):393-402. doi:10.1007/s00228-019-02801-2

125. Minami S, Fujimoto K, Ogata Y, Yamamoto S, Komuta K. Opioids have no negative effect on the survival time of patients with advanced lung cancer in an acute care hospital. Support Care Cancer. 2015;23(8):2245-2254. doi:10.1007/s00520-014-2592-6

126. Sathornviriyapong A, Nagaviroj K, Anothaisintawee T. The association between different opioid doses and the survival of advanced cancer patients receiving palliative care. BMC Palliat Care. 2016;15(1):95. doi:10.1186/s12904-016-0169-5

127. Zylla D, Steele G, Shapiro A, Richter S, Gupta P. Impact of opioid use on health care utilization and survival in patients with newly diagnosed stage IV malignancies. Support Care Cancer. 2018;26(7):2259-2266. doi:10.1007/s00520-018-4062-z

128. Hasegawa T, Oguri T, Osawa $T$, et al. Opioid dose and survival of patients with incurable nonsmall cell lung cancer: a prospective cohort study. $J$ Palliat Med. 2018;21(10):1436-1441. doi:10.1089/jpm.2018.0044

129. Zimmers TA, Fishel ML, Bonetto A. STAT3 in the systemic inflammation of cancer cachexia. Semin Cell Dev Biol. 2016;54:28-41. doi:10.1016/j.semcdb.2016.02.009

130. Tuomisto AE, Mäkinen MJ, Väyrynen JP. Systemic inflammation in colorectal cancer: underlying factors, effects, and prognostic significance. World J Gastroenterol. 2019;25(31):4383-4404. doi:10.3748/wjg.v25.i31.4383

131. Janku F, Johnson LK, Karp DD, Atkins JT, Singleton PA, Moss J. Treatment with methylnaltrexone is associated with increased survival in patients with advanced cancer. Ann Oncol. 2016;27 (11):2032-2038. doi:10.1093/annonc/mdw317

132. Ekholm O, Kurita GP, Hjsted J, Juel K, Sjgren P. Chronic pain, opioid prescriptions, and mortality in Denmark: a population-based cohort study. Pain. 2014;155(12):2486-2490. doi:10.1016/j.pain.2014.07.006

133. Wiese AD, Griffin MR, Schaffner W, et al. Opioid analgesic use and risk for invasive pneumococcal diseases. Ann Intern Med. 2018;168(6):396-404. doi:10.7326/M17-1907

134. Wiese AD, Griffin MR, Stein CM, Mitchel EF, Grijalva CG. Opioid analgesics and the risk of serious infections among patients with rheumatoid arthritis: a self-controlled case series study. Arthritis Rheumatol. 2016;68(2):323-331. doi:10.1002/art.39462

135. Eisenstein TK. The role of opioid receptors in immune system function. Front Immunol. 2019;10:2904. doi:10.3389/ fimmu.2019.02904

136. Suzuki M, Sakurada T, Gotoh K, Watanabe S, Satoh N. Correlation between the administration of morphine or oxycodone and the development of infections in patients with cancer pain. Am J Hosp Palliat Care. 2013;30(7):712-716. doi:10.1177/1049909112469823

137. Shao Y-J, Liu W-S, Guan B-Q, et al. Contribution of opiate analgesics to the development of infections in advanced cancer patients. Clin J Pain. 2017;33(4):295-299. doi:10.1097/ AJP.0000000000000405

138. Peterson PK, Gekker G, Hu S, et al. Morphine amplifies HIV-1 expression in chronically infected promonocytes cocultured with human brain cells. J Neuroimmunol. 1994;50(2):167-175. doi:10.1016/0165-5728(94)90043-4
139. Ho W-Z, Guo C-J, Yuan C-S, Douglas SD, Moss J. Methylnaltrexone antagonizes opioid-mediated enhancement of HIV infection of human blood mononuclear phagocytes. J Pharmacol Exp Ther. 2003;307(3):1158-1162. doi:10.1124/ jpet.103.056697

140. Liao Y, Jiang J, Liang B, et al. Opiate use inhibits TLR9 signaling pathway in vivo: possible role in pathogenesis of HIV-1 infection. Sci Rep. 2017;7(1):13071. doi:10.1038/s41598-017-12066-3

141. Sobanski P, Krajnik M, Shaqura M, Bloch-Boguslawska E, Schäfer M, Mousa SA. The presence of mu-, delta-, and kappa-opioid receptors in human heart tissue. Heart Vessels. 2014;29(6):855-863. doi:10.1007/s00380-013-0456-5

142. Hobl E-L, Stimpfl T, Ebner J, et al. Morphine decreases clopidogrel concentrations and effects: a randomized, double-blind, placebo-controlled trial. $J$ Am Coll Cardiol. 2014;63 (7):630-635. doi:10.1016/j.jacc.2013.10.068

143. Carman WJ, Su S, Cook SF, Wurzelmann JI, McAfee A. Coronary heart disease outcomes among chronic opioid and cyclooxygenase-2 users compared with a general population cohort. Pharmacoepidemiol Drug Saf. 2011;20(7):754-762. doi:10.1002/pds.2131

144. Dimsdale JE, Norman D, DeJardin D, Wallace MS. The effect of opioids on sleep architecture. J Clin Sleep Med. 2007;3(1):33-36.

145. Eacret D, Veasey SC, Blendy JA. Bidirectional relationship between opioids and disrupted sleep: putative mechanisms. Mol Pharmacol. 2020;98(4):445-453. doi:10.1124/mol.119.119107

146. Correa D, Farney RJ, Chung F, Prasad A, Lam D, Wong J. Chronic opioid use and central sleep apnea: a review of the prevalence, mechanisms, and perioperative considerations. Anesth Analg. 2015;120(6):1273-1285. doi:10.1213/ ANE.0000000000000672

147. Good P, Pinkerton R, Bowler S, Craig J, Hardy J. Impact of opioid therapy on sleep and respiratory patterns in adults with advanced cancer receiving palliative care. J Pain Symptom Manage. 2018;55(3):962-967. doi:10.1016/j. jpainsymman.2017.11.026

148. Walker JM, Farney RJ, Rhondeau SM, et al. Chronic opioid use is a risk factor for the development of central sleep apnea and ataxic breathing. J Clin Sleep Med. 2007;3(5):455-461. doi:10.5664/ jesm. 26908

149. Farney RJ, McDonald AM, Boyle KM, et al. Sleep disordered breathing in patients receiving therapy with buprenorphine/naloxone. Eur Respir J. 2013;42(2):394-403. doi:10.1183/ 09031936.00120012

150. Selim BJ, Koo BB, Qin L, et al. The association between nocturnal cardiac arrhythmias and sleep-disordered breathing: the DREAM study. $J$ Clin Sleep Med. 2016;12(6):829-837. doi: $10.5664 /$ jcsm. 5880

151. Young T, Finn L, Peppard PE, et al. Sleep disordered breathing and mortality: eighteen-year follow-up of the Wisconsin sleep cohort. Sleep. 2008;31(8):1071-1078.

152. Jehangir W, Karabachev AD, Mehta Z, Davis M. Opioid-related sleep-disordered breathing: an update for clinicians. Am J Hosp Palliat Med. 2020;37(11):970-973. doi:10.1177/ 1049909120913232

153. Kalso E, Edwards JE, Moore AR, McQuay HJ. Opioids in chronic non-cancer pain: systematic review of efficacy and safety. Pain. 2004;112(3):372-380. doi:10.1016/j. pain.2004.09.019

154. Khademi H, Kamangar F, Brennan P, Malekzadeh R. Opioid therapy and its side effects: a review. Arch Iran Med. 2016;19 (12):870-876.

155. Sandgren JE, McPhee MS, Greenberger NJ. Narcotic bowel syndrome treated with clonidine. Resolution of abdominal pain and intestinal pseudo-obstruction. Ann Intern Med. 1984;101 (3):331-334. doi:10.7326/0003-4819-101-3-331 
156. Drossman D, Szigethy E. The narcotic bowel syndrome: a recent update. Am J Gastroenterol Suppl. 2014;2(1):22-30. doi:10.1038/ ajgsup. 2014.6

157. Choung RS, Locke GR, Zinsmeister AR, Schleck CD, Talley NJ. Opioid bowel dysfunction and narcotic bowel syndrome: a population-based study. Am J Gastroenterol. 2009;104 (5):1199-1204. doi:10.1038/ajg.2009.71

158. Farmer AD, Gallagher J, Bruckner-Holt C, Aziz Q. Narcotic bowel syndrome. Lancet Gastroenterol Hepatol. 2017;2 (5):361-368. doi:10.1016/S2468-1253(16)30217-5

159. Grunkemeier DMS, Cassara JE, Dalton CB, Drossman DA. The narcotic bowel syndrome: clinical features, pathophysiology, and management. Clin Gastroenterol Hepatol. 2007;5(10):1126-1139. doi:10.1016/j.cgh.2007.06.013

160. Akbarali HI, Dewey WL. Gastrointestinal motility, dysbiosis and opioid-induced tolerance: is there a link? Nat Rev Gastroenterol Hepatol. 2019;16(6):323-324. doi:10.1038/s41575-019-0150-x

161. Wang F, Meng J, Zhang L, Johnson T, Chen C, Roy S. Morphine induces changes in the gut microbiome and metabolome in a morphine dependence model. Sci Rep. 2018;8(1):3596. doi:10.1038/s41598-018-21915-8

162. Acharya C, Betrapally NS, Gillevet PM, et al. Chronic opioid use is associated with altered gut microbiota and predicts readmissions in patients with cirrhosis. Aliment Pharmacol Ther. 2017;45 (2):319-331. doi:10.1111/apt.13858

163. Ren M, Lotfipour S. The role of the gut microbiome in opioid use. Behav Pharmacol. 2020;31(2 \& 3):113-121. doi:10.1097/ FBP.0000000000000538

164. Taylor A. Revealing a brain-gut microbiome connection following chronic opioid treatment. J Pain. 2018;19(3):S1. doi:10.1016/ j.jpain.2017.12.012

165. Banerjee S, Sindberg G, Wang F, et al. Opioid-induced gut microbial disruption and bile dysregulation leads to gut barrier compromise and sustained systemic inflammation. Mucosal Immunol. 2016;9(6):1418-1428. doi:10.1038/mi.2016.9

166. Touw K, Ringus DL, Hubert N, et al. Mutual reinforcement of pathophysiological host-microbe interactions in intestinal stasis models. Physiol Rep. 2017;5(6):e13182. doi:10.14814/phy2.13182

167. Hanks GW, Hoskin PJ, Aherne GW, Chapman D, Turner P, Poulain P. Enterohepatic circulation of morphine. Lancet. 1988;331(8583):469. doi:10.1016/S0140-6736(88)91256-1

168. Bauman BD, Meng J, Zhang L, et al. Enteric glial-mediated enhancement of intestinal barrier integrity is compromised by morphine. J Surg Res. 2017;219:214-221. doi:10.1016/j. jss.2017.05.099

169. Kang M, Mischel RA, Bhave S, et al. The effect of gut microbiome on tolerance to morphine mediated antinociception in mice. Sci Rep. 2017. Available from https:/www.ncbi.nlm.nih. gov/pmc/articles/PMC5314392.

170. Larney S, Tran LT, Leung J, et al. All-cause and cause-specific mortality among people using extramedical opioids: a systematic review and meta-analysis. JAMA Psychiatr. 2020;77(5):493-502. doi:10.1001/jamapsychiatry.2019.4170

171. Dunn KM, Saunders KW, Rutter CM, et al. Opioid prescriptions for chronic pain and overdose: a cohort study. Ann Intern Med. 2010;152(2):85-92. doi:10.7326/0003-4819-152-2-20100119000006

172. Kaplovitch E, Gomes T, Camacho X, Dhalla IA, Mamdani MM, Juurlink DN. Sex differences in dose escalation and overdose death during chronic opioid therapy: a population-based cohort study. PLoS One. 2015;10(8):e0134550. doi:10.1371/journal. pone. 0134550

173. Gomes T, Mamdani MM, Dhalla IA, Paterson JM, Juurlink DN. Opioid dose and drug-related mortality in patients with nonmalignant pain. Arch Intern Med. 2011;171(7):686-691. doi:10.1001/archinternmed.2011.117
174. Miller M, Barber CW, Leatherman S, et al. Prescription opioid duration of action and the risk of unintentional overdose among patients receiving opioid therapy. JAMA Intern Med. 2015;175 (4):608-615. doi:10.1001/jamainternmed.2014.8071

175. Chung CP, Dupont WD, Murray KT, Hall K, Stein CM, Ray WA. Comparative out-of-hospital mortality of long-acting opioids prescribed for non-cancer pain: a retrospective cohort study. Pharmacoepidemiol Drug Saf. 2019;28(1):48-53. doi:10.1002/ pds.4619

176. Zeng C, Dubreuil M, LaRochelle MR, et al. Association of tramadol with all-cause mortality among patients with osteoarthritis. JAMA. 2019;321(10):969-982. doi:10.1001/ jama.2019.1347

177. Aroke HA, Buchanan AL, Bratberg J, et al. Initial patterns of prescription opioid supply and risk of mortality among insured adults in the United States. J Addict Med. 2021;15(2):99-108. doi:10.1097/ADM.0000000000000701

178. Krebs EE, Becker WC, Zerzan J, Bair MJ, McCoy K, Hui S. Comparative mortality among Department of Veterans Affairs patients prescribed methadone or long-acting morphine for chronic pain. Pain. 2011;152(8):1789-1795. doi:10.1016/j. pain.2011.03.023

179. Gomes T, Juurlink DN, Antoniou T, Mamdani MM, Paterson JM, van den Brink W. Gabapentin, opioids, and the risk of opioid-related death: a population-based nested case-control study. PLoS Med. 2017;14(10):e1002396. doi:10.1371/journal. pmed.1002396

180. Gomes T, Juurlink DN, Dhalla IA, Mailis-Gagnon A, Paterson JM, Mamdani MM. Trends in opioid use and dosing among socio-economically disadvantaged patients. Open Med. 2011;5(1):e13-22.

181. Brennan F, Lohman D, Gwyther L. Access to pain management as a human right. Am J Public Health. 2019;109:61-65. doi:10.2105/AJPH.2018.304743

182. Makhlouf SM, Pini S, Ahmed S, Bennett MI. Managing pain in people with cancer-a systematic review of the attitudes and knowledge of professionals, patients, caregivers and public. $J$ Cancer Educ. 2020;35(2):214-240. doi:10.1007/s13187-01901548-9

183. Khosrow-Khavar F, Kurteva S, Cui Y, Filion KB, Douros A. Opioids and the risk of infection: a critical appraisal of the pharmacologic and clinical evidence. Expert Opin Drug Metab Toxicol. 2019;15(7):565-575. doi:10.1080/ 17425255.2019.1634053

184. Dhindsa S, Prabhakar S, Sethi M, Bandyopadhyay A, Chaudhuri A, Dandona P. Frequent occurrence of hypogonadotropic hypogonadism in type 2 diabetes. J Clin Endocrinol Metab. 2004;89(11):5462-5468. doi:10.1210/jc.2004-0804

185. Woolf PD, Hamill RW, McDonald JV, Lee LA, Kelly M. Transient hypogonadotropic hypogonadism caused by critical illness. J Clin Endocrinol Metab. 1985;60(3):444-450. doi:10.1210/jcem-60-3-444

186. Ensrud KE, Blackwell T, Mangione CM, et al. Central nervous system active medications and risk for fractures in older women. Arch Intern Med. 2003;163(8):949-957. doi:10.1001/ archinte.163.8.949

187. Landi F, Onder G, Cesari M, et al. Psychotropic medications and risk for falls among community-dwelling frail older people: an observational study. J Gerontol a Biol Sci Med Sci. 2005;60 (5):622-626. doi:10.1093/gerona/60.5.622

188. Kotlinska-Lemieszek A, Klepstad P, Haugen DF. Clinically significant drug-drug interactions involving opioid analgesics used for pain treatment in patients with cancer: a systematic review. Drug Des Devel Ther. 2015;9:5255-5267. doi:10.2147/DDDT. S86983 


\section{Publish your work in this journal}

Drug Design, Development and Therapy is an international, peerreviewed open-access journal that spans the spectrum of drug design and development through to clinical applications. Clinical outcomes, patient safety, and programs for the development and effective, safe, and sustained use of medicines are a feature of the journal, which has also been accepted for indexing on PubMed Central. The manuscript management system is completely online and includes a very quick and fair peer-review system, which is all easy to use. Visit http://www. dovepress.com/testimonials.php to read real quotes from published authors. 